\title{
Prevalence of asthma in adults in Busselton, Western Australia
}

\author{
Jennifer K Peat, Michelle Haby, Jon Spijker, Geoffrey Berry, Ann J Woolcock
}

Abstract

Objective-To estimate whether the prevalence of asthma in adults increased over a nine year interval.

Design-Serial cross sectional studies of the population with a protocol that included both subjective and objective measurements.

Setting-Busselton, Western Australia.

Subjects-A random sample of 553 subjects aged 18-55 years in 1981, and of 1028 subjects aged 18-55 years in 1990 .

Main outcome measures-Respiratory symptoms measured by self administered questionnaire, bronchial responsiveness measured by bronchial challenge with histamine, and allergy measured by skin prick tests.

Results-Symptoms with increased prevalence were those with significant association with allergy in this population. Recent wheeze increased from $17.5 \%$ to $28.8 \%(p<0.001)$ and diagnosed asthma increased from $9.0 \%$ to $16.3 \% \quad(p<0.001)$. The increase was greatest in subjects less than 30 years old. The prevalence of shortness of breath coming on at rest and of hay fever also increased significantly, but the prevalence of shortness of breath on exertion, chronic cough, bronchial hyperresponsiveness, current asthma (defined as recent wheeze plus bronchial hyperresponsiveness), and allergy did not increase. The severity of bronchial responsiveness did not change significantly in any symptom group.

Conclusions-Young adults showed a significant increase in reporting of symptoms related to allergy but not in the prevalence of current asthma. The increase in symptoms may be due to increased awareness of asthma in this community, to changed treatment patterns, or to increased exposures to allergens.

\section{Introduction}

Patterns of asthma may be changing. Hospital admission rates for childhood asthma are increasing in many Westernised countries. ${ }^{12}$ The cumulative prevalence of childhood wheeze in Australia is also increasing, ${ }^{3}$ as is the prevalence of recent wheeze in England and Wales. ${ }^{45}$ Most prevalence studies, however, have based their estimates solely on questionnaire responses, thereby incurring methodological problems in their approach. Because these responses are influenced by a wide range of subjective factors including local diagnostic practices, cultural characteristics, and accuracy of recall, such data must be treated with caution. The prevalence of asthma may have increased, but equally the measured increase may be attributable, in part at least, to improved awareness of disease. This is especially likely in the wake of education campaigns such as the National Asthma Campaign in Australia that have been expressly designed to increase this awareness.

To date there are no reports of a change in the prevalence of asthma in adults, and only one report of increased prevalence in children has included an objective measure of bronchial responsiveness. ${ }^{5}$ In 1981 we conducted a cross sectional study of a random sample of the adult population of Busselton, Western Australia, with a standard protocol that included both subjective and objective methods to measure asthma and allergy. ${ }^{6}$ In 1990 , to estimate whether the prevalence of asthma had changed over the nine year interval, we used the same methods in a second cross sectional study of the population.

\section{Methods \\ SUBJECTS}

1981 Study-In 1981, the adult population of Busselton, which was estimated to be about 6000 , was asked to attend a health survey. ${ }^{6}$ Of the 3590 subjects who attended, one in four was assigned randomly to our study. A total of 1170 subjects were studied, of whom 922 were selected on the basis of age, sex, and socioeconomic status to represent the population at that time. The 922 subjects were aged 18-79, but only the data for subjects aged 18-55 have been included in the current analyses.

1990 Study-In 1990, a second cross sectional sample was studied. Screening questionnaires comprising 12 questions about wheeze, shortness of breath, and cough in the past 12 months were sent to approximately 9000 people on the town's electoral roll. From those who returned the questionnaire, a random sample stratified for age and sex of subjects below the age of 55 years was invited by telephone to attend for study. Non-attenders were replaced by a second randomly selected subject from their age-sex stratum A total of 100 non-attenders was surveyed by telephone and asked two questions about recent wheeze and recent use of drugs for asthma.

RESPIRATORY SYMPTOMS

In both studies a self administered questionnaire was used to collect details of history of respiratory illness. In 1981, the Medical Research Council questionnaire was used. In 1990, this was replaced by a modification of the International Union against Tuberculosis and Lung Disease questionnaire reported to discriminate symptoms of asthma better. ${ }^{8}$ Only the questions that were most similar have been used to compare symptom rates reported by various criteria. Subjects with a positive response to "Have you ever had asthma diagnosed by a doctor?" were classified as having "doctor diagnosed asthma." Subjects with a positive response to "Have you ever had wheezing or tightnes (1981) whistling (1990) in the chest?" were classified as having "wheeze ever." In 1981, subjects were asked "Are the symptoms still present?" and, in 1990, if they had experienced "wheezing or whistling at any time in the past 12 months." Positive responses to these questions were used to classify "recent wheeze." Questions worded almost exactly the same in both studies were asked about cough on most mornings for at least three months of the year (chronic cough) cough that caused night waking (night cough); and shortness of breath that came on at rest or while walking up a hill or that prevented keeping pace with other adults of the same age.

\section{BRONCHIAL RESPONSIVENESS}

Both studies included a histamine bronchial challenge test, given by the rapid method. ${ }^{9} \mathrm{~A}$ team trained and employed by the reporting department carried out all challenges. In 1981, lung function was recorded by Vitalograph spirometers and in 1990, by rolling seal spirometers connected to IBM-PC computers for immediate data acquisition. Forced expiratory measures were repeated until two readings of forced expiratory volume in one second and forced vital capacity, reproducible to $100 \mathrm{ml}$, were obtained, of
Correspondence to: Professor Ann J Woolcock, Institute of Respiratory Medicine, Royal Prince NSW 2050, Australia. 
which the largest value was used in analyses. Subjects who had taken a $\beta$ agonist within six hours or theophylline within 12 hours of presenting were asked to withhold medication before returning for later testing. Histamine diphosphate was given with $\mathrm{De}$ Vilbiss hand held nebulisers in doses ranging from 0.03 to $3.9 \mu \mathrm{mol}$ histamine. The test was stopped if forced expiratory volume in one second fell by $20 \%$ or more or if all histamine dose steps to $3.9 \mu \mathrm{mol}$ had been given. Salbutamol aerosol was given to aid recovery when necessary.

A dose-response curve was plotted as the percent change in forced expiratory volume in one second from the post-saline (control) value against the logarithm of the dose of histamine. For subjects who experienced a fall of $20 \%$ or greater, the dose of histamine that caused a $20 \%$ fall was calculated. Subjects with such a fall were classified as having bronchial hyperresponsiveness and the remainder with "censored" values as having normal responsiveness. Dose-response ratio was calculated for all subjects as the percentage fall in forced expiratory volume in one second at the last dose, divided by total dose given. ${ }^{10}$ Because many subjects had a forced expiratory volume in one second that remained stable or improved slightly during bronchial challenge, and thus gave a zero or negative doseresponse ratio value, a constant of 3 was added to all dose-response ratios to obtain a positive value for logarithmic conversion. " Dose-response ratio values are indicated by units $\left(\%\right.$ fall $\left.\mathrm{FEV}_{1} / \mu \mathrm{mol}\right)+3$ or, for brevity, $\%$ fall $\mathrm{FEV}_{1} / \mu \mathrm{mol}+3$.

Subjects who presented with a forced expiratory volume in one second less than $60 \%$ of predicted ${ }^{12}$ did not undergo histamine challenge but were given a bronchodilator challenge. After measurement of baseline lung function, salbutamol was given and lung function measured again at 10 minutes. Subjects with an increase of $15 \%$ or more in volume were considered to have a positive bronchodilator challenge.

ALLERGY

Allergy was measured by skin prick test reactions to allergens applied to the forearm. ${ }^{13}$ Histamine and

TABLE I-Prevalence (\%) of respiratory illness in previous 12 months measured by screening questionnaire in 5020 subjects aged 18-84 years in 1990

\begin{tabular}{lc}
\hline Symptom & $\begin{array}{c}\text { Prevalence } \\
\text { (95\% confidence } \\
\text { interval) }\end{array}$ \\
\hline Wheeze or whistling in chest & $24 \cdot 2(23 \cdot 0$ to $25 \cdot 4)$ \\
Woken with chest tightness & $18 \cdot 7(17 \cdot 6$ to $19 \cdot 8)$ \\
Woken with shortness of breath & $16 \cdot 8(15 \cdot 8$ to $17 \cdot 8)$ \\
Woken by attack of coughing & $27 \cdot 0(25 \cdot 8$ to $28 \cdot 2)$ \\
Asthma attack & $8 \cdot 3(7.5$ to $9 \cdot 1)$ \\
Hay fever & $36 \cdot 6(35 \cdot 3$ to $37 \cdot 9)$ \\
\hline
\end{tabular}

TABLE II-Prevalence (\%) of symptoms measured by self administered questionnaire in 1981 and 1990

\begin{tabular}{|c|c|c|c|c|c|}
\hline & \multicolumn{2}{|c|}{ Prevalence } & \multirow{2}{*}{$\begin{array}{c}\text { Difference }(\%) \\
(95 \% \text { confidence } \\
\text { interval })\end{array}$} & \multirow[b]{2}{*}{$\mathrm{p}$ Value } & \multirow{2}{*}{$\begin{array}{l}\mathrm{p} \text { Value for } \\
\text { association with } \\
\text { atopy }(1990)\end{array}$} \\
\hline & $\begin{array}{c}1981 \\
(n=553)\end{array}$ & $\begin{array}{c}1990 \\
(n=1028)\end{array}$ & & & \\
\hline \multicolumn{6}{|l|}{ Cumulative prevalence: } \\
\hline Diagnosed asthma & $9 \cdot 0$ & $16 \cdot 3$ & $7 \cdot 3(4 \cdot 0$ to $10 \cdot 6)$ & $<0.001$ & $<0.001$ \\
\hline Wheeze ever & $26 \cdot 4$ & $36 \cdot 7$ & $10 \cdot 3(5 \cdot 6$ to $15 \cdot 0)$ & $<0.001$ & $<0.001$ \\
\hline \multicolumn{6}{|l|}{ Period prevalence: } \\
\hline Recent wheeze & $17 \cdot 5$ & $28 \cdot 8$ & $11 \cdot 3(7 \cdot 1$ to $15 \cdot 5)$ & $<0.001$ & $<0.001$ \\
\hline Hay fever & $21 \cdot 9$ & $46 \cdot 7$ & $24 \cdot 8(20 \cdot 2$ to $29 \cdot 4)$ & $<0.001$ & $<0.001$ \\
\hline \multicolumn{6}{|l|}{ Shortness of breath: } \\
\hline Coming on at rest & $4 \cdot 2$ & $15 \cdot 4$ & $11.2(8.4$ to 14.0$)$ & $<0.001$ & $<0.001$ \\
\hline On exercise & $19 \cdot 2$ & $20 \cdot 3$ & $1 \cdot 1(-3.0$ to 5.2$)$ & 0.6 & $<0.05$ \\
\hline When keeping pace & $6 \cdot 3$ & $7 \cdot 8$ & $1.5(-1.1$ to 4.1$)$ & 0.25 & $0 \cdot 25$ \\
\hline Chronic cough & $10 \cdot 7$ & $13 \cdot 1$ & $2.4(-0.9$ to 5.7$)$ & $0 \cdot 16$ & $<0.01$ \\
\hline Cough causing night waking & $25 \cdot 0$ & $29 \cdot 7$ & $4 \cdot 7(0 \cdot 1$ to $9 \cdot 3)$ & 0.04 & $<0.05$ \\
\hline \multicolumn{6}{|l|}{ Bronchial responsiveness and allergy: } \\
\hline Bronchial hyperresponsiveness & $10 \cdot 6$ & $7 \cdot 9$ & $-2.7(-5.8$ to 0.4$)$ & 0.07 & $<0.001$ \\
\hline Current asthma & $5 \cdot 4$ & $6 \cdot 3$ & $0.9(-1.5$ to 3.3$)$ & $0 \cdot 47$ & $<0.001$ \\
\hline \multicolumn{6}{|l|}{ Allergy: } \\
\hline House dust mite & $24 \cdot 9$ & $24 \cdot 5$ & $-0 \cdot 4(-4 \cdot 8$ to $4 \cdot 0)$ & 0.9 & \\
\hline Pollen & $28 \cdot 8$ & $28 \cdot 8$ & $0.0(-4.7$ to $4 \cdot 7)$ & 1.0 & \\
\hline All atopy & $38 \cdot 5$ & $41 \cdot 2$ & $2 \cdot 7(-2 \cdot 3$ to $7 \cdot 7)$ & 0.3 & \\
\hline
\end{tabular}

saline were used as positive and negative controls. After 15 minutes, wheal size was recorded as the long axis and its perpendicular; an average of these measurements was used in analysis. A skin prick reaction was regarded as positive if the wheal size was $4 \mathrm{~mm}$ or greater. Only sensitivities to comparable allergens from the panels tested are reported. The house dust mite allergen Dermatophagoides farinae was obtained from the same supplier at each study. The allergen orchard grass, which was tested in 1981, was replaced by timothy grass in 1990. Subjects were considered sensitised to pollens if they had a positive reaction to orchard grass, rye grass, or plantain in 1981 and to timothy grass, rye grass, or plantain in 1990. In both years, atopy was defined as one or more positive reactions to the house dust mite, pollen, or Alternaria tenuis allergens.

\section{STATISTICAL METHODS}

Data were analysed with the SAS statistical package. Geometric mean values are reported for both doseresponse ratio and $20 \%$ fall in forced expiratory volume in one second, which were converted to base 10 logarithms before analysis. Prevalence figures and mean values are given with $95 \%$ confidence intervals. $\chi^{2}$ tests were used to determine the significance of differences in prevalence between years. Student's $t$ test was used to determine the significance of differences between mean values of continuous variables. Logistic regression was used to compute odds ratios adjusted for sensitivity in all allergen groups.

\section{Results}

A total of 553 subjects were selected from the sample of 922 subjects studied in 1981 on the basis that they were aged $18-55$ years; $50.5 \%$ were men, $24.0 \%$ were former smokers, and $19.9 \%$ were current smokers. The mean (SD) age of the men was $37.4(10 \cdot 3)$ years and of the women was $38 \cdot 7(10 \cdot 2)$ years.

In 1990 a screening questionnaire was mailed to approximately 9000 adults, of whom 5020 subjects $(56 \%)$ responded. Table I shows the prevalence of respiratory symptoms in this sample. From the 2691 subjects aged 18-55 years who returned a screening questionnaire a random stratified sample was invited for study, of whom 1028 attended; $55 \cdot 1 \%$ were men, $29.1 \%$ were former smokers, and $15.4 \%$ were current smokers. The mean age of the men was $37 \cdot 3(9 \cdot 2)$ years and of the women was $38 \cdot 0(9 \cdot 1)$ years. The proportion who had used a drug for asthma ( $\beta$ agonist, corticosteroids, or sodium cromoglycate) in the past 12 months was $10 \cdot 2 \%$ ( $95 \%$ confidence interval 9.4 to $11 \cdot 0)$. A telephone survey of 100 subjects selected for full study but who failed to attend ( $59 \%$ men) showed that $19 \%(11.3 \%$ to $26.7 \%)$ reported recent wheeze and $6 \%(1.4 \%$ to $10 \cdot 7 \%)$ had recently used a drug for asthma. These rates were not significantly different from those in the sample studied.

Table II shows the cumulative and current prevalence of respiratory symptoms measured by questionnaire in the cross sectional samples of 18-55 year old subjects in 1981 and in 1990 . The prevalence of diagnosed asthma almost doubled and that of recent hay fever more than doubled over the nine year period. The prevalence of wheeze ever, recent wheeze, and shortness of breath coming on spontaneously at rest also increased significantly. The prevalence of chronic cough, cough causing waking, and shortness of breath associated with exercise did not change significantly. The symptoms which increased significantly were those that had the most significant association with allergy, as measured by univariate $\chi^{2}$ test, whereas those that did not increase in prevalence had a lesser association with allergy. Most of the increase in the 
prevalence of diagnosed asthma was in subjects under the age of 40 years and most of the increase in both the cumulative and period prevalence of wheeze and shortness of breath coming on at rest was in subjects under 30 (table III). Cough also increased more in this age group, but hay fever increased equally in all age groups.

Table II shows that, overall, the prevalences of bronchial hyperresponsiveness and of allergy were similar in 1981 and 1990. In 1981, 13 subjects were omitted from a bronchial challenge because of poor resting lung function, of whom 11 had a positive bronchodilator response. In 1990, 16 subjects were omitted, of whom nine had a positive bronchodilator response. Inclusion of subjects with a positive bronchodilator response in the group with "current asthma" brought the prevalence of current asthma in 1981 to $7 \cdot 4 \%(5 \cdot 2 \%$ to $9 \cdot 6 \%)$ and in 1990 to $7 \cdot 2 \%$ $(6 \cdot 2 \%$ to $9 \cdot 4 \%)$. The prevalence of bronchial hyperresponsiveness and current asthma did not show a significant increase or decrease in any age group (table III).

The severity of bronchial responsiveness as measured by dose-response ratio was examined in subjects categorised by their symptom history (table IV). Subjects who reported wheeze that occurred more than 12 months previously were categorised as having "past wheeze." The only group in whom responsiveness increased was the recent wheeze group, and the increase, though significant at the $\mathrm{p}<0.05$ level, was not important clinically. There was no evidence of an increase in the severity of bronchial responsiveness in groups defined by allergic status.

The odds ratios for subjects having bronchial hyperresponsiveness or current asthma in 1990 associated with sensitisation to a particular allergen, and adjusted for sensitisation to other allergens, are shown in table V. Subjects with allergy to either house dust mites or cats had a significantly increased risk of having

TABLE III-Difference in prevalence of symptoms between 1981 and 1990 studies by age group

\begin{tabular}{|c|c|c|c|}
\hline & \multicolumn{3}{|c|}{ Difference in prevalence $(\%)(95 \%$ confidence interval) } \\
\hline & $18-29$ years & $30-39$ years & $40-55$ years \\
\hline \multicolumn{4}{|l|}{ No in groups: } \\
\hline 1981 & 138 & 173 & 242 \\
\hline 1990 & 252 & 347 & 428 \\
\hline \multicolumn{4}{|l|}{ Cumulative prevalence: } \\
\hline Diagnosed asthma & $12 \cdot 2(5 \cdot 7$ to $18 \cdot 7)$ & $10 \cdot 0(4 \cdot 1$ to $15 \cdot 9)$ & $1.5(-3.6$ to 6.6$)$ \\
\hline Wheeze ever & $23 \cdot 5(14 \cdot 8$ to $32 \cdot 2)$ & $11.5(3.0$ to 20.0$)$ & $1.6(-5.7$ to 8.9$)$ \\
\hline \multicolumn{4}{|l|}{ Period prevalence: } \\
\hline Recent wheeze & $22 \cdot 6(14 \cdot 0$ to $31 \cdot 2)$ & $8.5(0.9$ to $16 \cdot 1)$ & $5 \cdot 6(-0.9$ to $12 \cdot 1)$ \\
\hline Hay fever & $26.4(17.4$ to 35.4$)$ & $23.3(15 \cdot 1$ to $31 \cdot 5)$ & $26.3(19.2$ to 33.4$)$ \\
\hline \multicolumn{4}{|l|}{ Shortness of breath: } \\
\hline Coming on at rest & $15 \cdot 8(10 \cdot 3$ to 21.3$)$ & $8.0(2.9$ to 13.1$)$ & $11 \cdot 0(6 \cdot 9$ to $15 \cdot 1)$ \\
\hline On exercise & $7 \cdot 1(-1 \cdot 6$ to $15 \cdot 8)$ & $0.0(-6.0$ to 6.0$)$ & $-1.3(-7.8$ to $5 \cdot 2)$ \\
\hline When keeping pace & $2.3(-1.6$ to 6.2$)$ & $0.2(-4.9$ to 5.7$)$ & $1.6(-2.5$ to 5.7$)$ \\
\hline Chronic cough & $11.8(5 \cdot 5$ to $18 \cdot 1)$ & $-0.6(-5 \cdot 3$ to $4 \cdot 1)$ & $-0.4(-5.5$ to 4.7$)$ \\
\hline Cough causing night waking & $10 \cdot 6(1.4$ to $19 \cdot 8)$ & $6 \cdot 2(-2 \cdot 0$ to $14 \cdot 4)$ & $-1 \cdot 2(-8 \cdot 1$ to $5 \cdot 7)$ \\
\hline \multicolumn{4}{|l|}{ Bronchial responsiveness: } \\
\hline Bronchial hyperresponsiveness & $-2 \cdot 0(-8 \cdot 7$ to $4 \cdot 7)$ & $-4.3(-9.6$ to 1.0$)$ & $-3 \cdot 1(-7 \cdot 4$ to $1 \cdot 2)$ \\
\hline Current asthma & $4.3(-0.6$ to 9.2$)$ & $-1 \cdot 4(-5 \cdot 9$ to $3 \cdot 1)$ & $-0.3(-3 \cdot 7$ to $3 \cdot 1)$ \\
\hline
\end{tabular}

TABLE IV-Mean dose-response ratio $\left(\%\right.$ fall $\left.F E V_{1} / \mu m o l+3\right)$ in subjects divided into groups according to history of respiratory illness or atopic status

\begin{tabular}{|c|c|c|c|c|c|}
\hline & \multicolumn{2}{|r|}{1981} & \multicolumn{2}{|r|}{1990} & \multirow[b]{2}{*}{$\begin{array}{l}\mathrm{p} \text { Value fo } \\
\text { difference }\end{array}$} \\
\hline & No & $\begin{array}{c}\text { Mean ( } 95 \% \\
\text { confidence interval) }\end{array}$ & No & $\begin{array}{c}\text { Mean (95\% } \\
\text { confidence interval) }\end{array}$ & \\
\hline \multicolumn{6}{|l|}{ History of respiratory symptoms: } \\
\hline \multicolumn{6}{|l|}{ Neither wheeze nor bronchial } \\
\hline hyperresponsiveness & 388 & $3.5(3.3$ to 3.8$)$ & 644 & $3.4(3.2$ to 3.6$)$ & $0 \cdot 1$ \\
\hline Past wheeze & 38 & $3.5(3.1$ to 4.0$)$ & 74 & $3 \cdot 4(3 \cdot 2$ to $3 \cdot 7)$ & 0.9 \\
\hline Recent wheeze & 67 & $4 \cdot 4(4 \cdot 0$ to $4 \cdot 7)$ & 231 & $3.9(3.8$ to $4 \cdot 1)$ & $<0.05$ \\
\hline \multicolumn{6}{|l|}{ Bronchial hyperresponsiveness but } \\
\hline no wheeze & 30 & $13.8(10.4$ to 18.3$)$ & 16 & $17 \cdot 2(12.6$ to $23 \cdot 5)$ & 0.3 \\
\hline Current asthma & 30 & $25.5(17.6$ to 36.9$)$ & 63 & $29 \cdot 1(21.7$ to $39 \cdot 0)$ & $0 \cdot 6$ \\
\hline \multicolumn{6}{|l|}{ Allergy: } \\
\hline All atopy & 210 & $5 \cdot 1(4 \cdot 6$ to $5 \cdot 8)$ & 424 & $5 \cdot 0(4 \cdot 6$ to $5 \cdot 5)$ & $0 \cdot 8$ \\
\hline Pollens & 145 & $5 \cdot 1(4 \cdot 6$ to $5 \cdot 9)$ & 296 & $5 \cdot 0(4 \cdot 5$ to $5 \cdot 5)$ & $0 \cdot 7$ \\
\hline House dust mite & 178 & $5 \cdot 3(4 \cdot 7$ to $6 \cdot 0)$ & 252 & $5.7(5.0$ to 6.5$)$ & 0.5 \\
\hline
\end{tabular}

TABLE $\mathrm{v}$-Risk of subjects having bronchial hyperresponsiveness or current asthma in 1990 and in presence of sensitivity to individual allergens, adjusted for sensitivity to other allergens

\begin{tabular}{lccccc}
\hline & \multicolumn{2}{c}{$\begin{array}{c}\text { Bronchial } \\
\text { hyperresponsiveness }\end{array}$} & & Current asthma \\
\cline { 2 - 3 } \cline { 5 - 6 } & $\begin{array}{c}\text { Adjusted odds ratio } \\
(95 \% \text { confidence } \\
\text { interval })\end{array}$ & p Value & $\begin{array}{c}\text { Adjusted odds ratio } \\
(95 \% \text { confidence } \\
\text { interval })\end{array}$ & p Value \\
Allergy & & & & \\
\hline $\begin{array}{l}\text { House dust } \\
\text { mite }\end{array}$ & $5.5(3.0$ to 10.4$)$ & $<0.001$ & & $6.6(3.2$ to 13.5$)$ & $<0.001$ \\
Cat & $3.1(1.8$ to 5.6$)$ & $<0.001$ & & $3.1(1.7$ to 5.6$)$ & $<0.001$ \\
Alternaria & $1.4(0.7$ to 3.0$)$ & 0.4 & & $1.6(0.7$ to 3.4$)$ & 0.3 \\
Rye grass & $1.0(0.6$ to 1.8$)$ & 0.9 & & $1.1(0.6$ to 1.9$)$ & 0.9 \\
\hline
\end{tabular}

bronchial hyperresponsiveness and current asthma. Allergy to Alternaria tenuis or ryegrass was not a significant risk factor for these conditions.

\section{Discussion}

We found that, in Busselton in the nine years 198190 , there was a significant increase in the diagnosis of asthma and a greater proportion of young adults were reporting both past and recent wheeze, hay fever, and other symptoms associated with allergy. However, the prevalence of sensitisation to common allergens and of bronchial hyperresponsiveness did not increase. The prevalence of current asthma hardly changed, being $7 \cdot 4 \%$ in 1981 and $7 \cdot 2 \%$ in 1990 . It is not known why a greater proportion of the community were experiencing respiratory symptoms in 1990. There may simply be an increased awareness of asthma, or it is possible that changed treatment practices or increased exposures to allergens have increased symptoms without increasing bronchial responsiveness.

\section{COMPARABILITY OF STUDIES}

The same inclusion criteria were used for both studies-that is, randomly selected volunteer attenders from the entire Busselton community who were aged 18-55. In both years, care was taken to maintain the population distributions of age and sex in the study samples. In 1981 the sample was also matched to the socioeconomic status of the population. ${ }^{6}$ In 1990 the non-responders were not significantly different from the study sample in terms of recent wheeze or use of drugs for asthma, although the lower rate of wheeze in non-responders suggests that subjects with asthmatic symptoms may have been more willing to participate. Although response rates in both years were slightly lower than expected, few population studies of adults that have included lung function testing have achieved higher attendance rates. Because the same research team conducted both studies with all observers trained to the same standard, comparisons of bronchial responsiveness are likely to be reliable.

Any studies conducted across time will inevitably suffer problems with changes to the protocol in line with current knowledge and technology. In our 1990 questionnaire we included questions reported to have better precision for measuring clinically important asthma ${ }^{8}$ but we maintained a number of core questions from 1981 on which we have based our comparisons. Because good comparability between the two questionnaires has been shown, ${ }^{14}$ this should not have influenced our findings significantly. The questions used to classify "recent wheeze" in both years were the most dissimilar, so that this comparison is likely to have the greatest error, but the questions on diagnosed asthma were virtually identical and the other questions had only slight word differences, which do not affect response. ${ }^{1516}$ There have been no similar studies of changes in symptom reporting in adults with which to 
compare our results, but studies of children in which the same questions have been used at a time interval show similar increases in the prevalence of asthma symptoms. ${ }^{3-5}$

For the 1990 study we updated our spirometers in order to use computerised data acquisition methods and to measure lung function as accurately as possible, but because measurement of bronchial responsiveness relies on percentage fall in forced expiratory volume in one second this would not have influenced measurements of a $20 \%$ fall or of dose-response ratios. We could not compare all allergen sensitivities because some allergens used in 1981 were not available or were excluded from our panel in 1990. Because most allergic subjects react to at least one of a few common allergens, ${ }^{17}$ these comparisons are likely to be reliable.

\section{COMPARABILITY OF ESTIMATES}

Any estimate of the prevalence of asthma obviously depends on the methods employed. Questionnaire estimates of the prevalence of self reported "current asthma" in Australian adults have varied from 5.6\%, to $7 \cdot 1 \%{ }^{19}$ and $7-8 \% .^{20}$ Rates of recent symptoms of wheeze collected by questionnaire are generally much higher. A study of 2198 adults selected from the electoral roll in Victoria found that $22 \%$ had recent wheeze, $19 \%$ had shortness of breath on exercise, and $13 \%$ had shortness of breath at rest. ${ }^{19}$ These figures were similar to those of our 1990 study. Slightly lower rates were reported from a New South Wales study in 1990 that used questionnaires mailed to parents of primary schoolchildren. In 13945 responders (a response rate of less than $54 \%$ ) there was $19 \%$ recent wheeze, $14 \%$ shortness of breath on exercise, and $16 \%$ morning tightness. ${ }^{20}$ It is difficult to compare our results of bronchial responsiveness with other studies of adults ${ }^{21}$ because different definitions have been used.

In the past decade there have been several high profile advertising and education campaigns specifically designed to increase community awareness of asthma and allergic symptoms, and the media have shown great interest in asthma. As a result medical practitioners may be more willing to diagnose and treat asthma. In 1990, almost as many adults in Busselton had used asthma drugs as had had recent symptoms, which does not suggest the same rate of undertreatment as found in children. ${ }^{22}$ Improved health awareness in this community was also reflected in the declining number of current smokers. From a public health viewpoint this is desirable, but, from an epidemiological viewpoint, changed awareness can substantially bias changes assessed by questionnaire.

\section{REASONS FOR DIFFERENCES}

Theoretically, any apparent increase in prevalence and morbidity due to asthma could result from changed labelling patterns, from more subjects having the disease, or from more severe illness in the same number of asthmatic patients. We found that the highest increases in reporting of symptoms occurred in younger adults, suggesting that if environmental conditions are responsible they must have changed within a specific time frame. We found no evidence that bronchial responsiveness or atopy had increased in prevalence or in severity in the period between studies. The prevalence of current asthma remained constant, and the subjects reporting wheeze in 1981 and in 1990 had similarly increased bronchial responsiveness. An increase in the prevalence of hay fever and of other symptoms closely associated with allergy strongly suggests that allergens are playing an important part in increasing illness, but we have no evidence of whether increased allergen load, such as house dust mite in homes, or increased susceptibility is responsible.

There is some evidence that regular use of $\beta$ agonists may worsen asthma, ${ }^{23}$ perhaps because bronchodilator treatment increases the allergen load inhaled; or it may increase bronchial responsiveness by unknown mechanisms. We found no evidence of increased bronchial responsiveness in the Busselton community, but the increase in symptoms associated with allergy supports the hypothesis of increased allergen inhalation. It is unfortunate that we did not collect data on use of $\beta$ agonists in the 1981 study for comparison.

A systematic surveillance of prevalence, severity, and morbidity from asthma is clearly required. Any such surveillance must collect data using standardised methods, including data of all known and putative risk factors. This will determine whether real changes in clinically important disease are taking place and whether such changes are a result of changing environmental conditions that alter allergen loads or of changing behavioural patterns, including those relating to use of asthma drugs. Because these factors are potentially preventable, further studies to elucidate their role are urgently required.

We thank the National Health and Medical Research Council, Allen and Hanburys, and the Community Health and Anti-Tuberculosis Association for funding the 1990 study and we thank the Busselton Population Studies Group for their cooperation. We also thank the research assistants who collected the data. We are especially grateful to $\mathrm{Mr}$ John Dermand of the Department of Medicine, University of Sydney, and to Ms Elspeth Inglis of the Busselton Community Health Centre for their organisation skills in sampling and contacting the subjects.

1 Mitchell EA. International trends in hospital admission rates for asthma. Arch Dis Child 1985;60:376-8.

2 Carman PG, Landau LI. Increased paediatric admissions with asthma in Western Australia: a problem of diagnosis? Med f Aust 1990;152:23-6.

3 Robertson CF, Heycock E, Bishop J, Nolan T, Olinsky A, Phelan P. Prevalence of asthma in Melbourne schoolchildren: changes over 26 years. $B M$ 1991;302:1116-8.

4 Burney PGJ, Chinn S, Rona RJ. Has the prevalence of asthma increased in children? Evidence from the national study of health and growth 1973-86. BMF 1990;300: 1306-10.

5 Burr ML, Butland BK, King S, Vaughan-Williams E. Changes in asthma prevalence: two surveys 15 years apart. Arch Dis Child 1989;64:1452-6.

6 Woolcock AJ, Peat JK, Salome CM, Yan K, Anderson SD, Schoeffel RE, et al. Prevalence of bronchial hyperresponsiveness and asthma in a rural adult population. Thorax 1987;42:361-8.

7 Committee on Research into Chronic Bronchitis. Questionnaire in respiratory symptoms and instructions for its use. London: Medical Research Council, 1966

8 Burney PGJ, Chinn S, Britton JR, Tattersfield AE, Papacosta AO. What symptoms predict the bronchial response to histamine? Evaluation in a community survey of the bronchial symptoms questionnaire (1984) of the International Union against Tuberculosis and Lung Disease. Int $\mathcal{f}$ Epidemiol 1989;18:165-73.

9 Yan K, Salome C, Woolcock AJ. Rapid method for measurement of bronchial responsiveness. Thorax 1983;38:760-5.

10 O'Connor G, Sparrow D, Taylor D, Segal M, Weiss S. Analysis of doseresponse curves to methacholine: an approach suitable for population response curves to methacholine: an appre

11 Peat JK, Salome CM, Berry G, Woolcock AJ. Relation of dose response slope to respiratory symptoms in a population of Australian schoolchildren.

12 Morris JF, Koski WA, Johnson LC. Spirometric standards for healthy non smoking adults. Am Rev Respir Dis 1971;103:56-67.

13 Pepys J. Types of allergic reaction. Clin Allergy 1973;3(suppl):491-509.

14 Abramson MJ, Hensley MJ, Saunders NA, Wlodarczyk JH. Evaluation of a new asthma questionnaire. $\mathcal{F}$ Asthma 1991;28:129-39.

15 Samet JM. A historical and epidemiological perspective on respiratory symptom questionnaires. Am $\mathcal{F}$ Epidemiol 1978;108:435-46.

16 Lebowitz MD, Burrows B. Comparison of questionnaires: the BMRC and NHLI respiratory questionnaires and a new self completion questionnaire. Am Rev Respir Dis 1976;113:627-35.

17 Peat JK, Woolcock AJ. Sensitivity to common allergens: relation to respiratory symptoms and bronchial hyper-responsiveness in children from three symptoms and bronchial hyper-responsiveness in children from

18 Campbell DA, Crockett AJ, McEvoy RD. South Australian asthma symptom prevalence study. Aust N Z F Med 1989;19 (suppl):657.

19 Abramson M, Kutin J, Bowes G. The prevalence of asthma in Victorian adults. Aust NZ J Med 1991;22:358-63.

20 Bauman A, Mitchell CA, Henry R, Robertson CF, Abramson MJ, Comino EJ, et al. Asthma morbidity in Australia: an epidemiological study. Med $\mathcal{f}$ Aus 1992;156:827-31.

21 Burney PGJ, Britton JR, Chinn S, Tattersfield AE, Papacosta AO, Kelson MC, et al. Descriptive epidemiology of bronchial reactivity in an adult population: results from a community survey. Thorax 1987;42:38-44.

22 Bauman $\mathrm{A}$, Young $\mathrm{L}$, Peat JK. Asthma under-recognition and undertreatmen in an Australian community. Aust N $Z \mathcal{F}$ Med 1992;22:36-40.

23 Pearce N, Crane J, Burgess C, Jackson R, Beasley R. Beta agonists and asthma mortality: déjà vu. Clin Exp Allergy 1991;21:401-10.

(Accepted 30 September 1992) 